\title{
Development of a New Fiberglass Reinforced Composite for Computer Aided Design - Computer Aided Manufacturing Applications in Dentistry
}

\begin{abstract}
MIHAI VARVARA ${ }^{1}$, RARES STIUFIUC ${ }^{2}$, VALENTIN TOMA ${ }^{2}$, CARINA CULIC ${ }^{1}$, DOINA PRODAN ${ }^{3}$, MEDA SIMU $^{1 *}$, CRISTINA GASPARIK ${ }^{1}$, ANCA MESAROS ${ }^{1}$, ALEXANDRU GRECU ${ }^{1}$, ALEXANDRU BURDE ${ }^{1}$, DIANA DUDEA ${ }^{1}$, BOGDAN CULIC ${ }^{1}$

IUniversity of Medicine and Pharmacy luliu Hatieganu, Faculty of Dentistry, Department of Prosthodontics, 8 Victor Babes Str., 400012, Cluj Napoca, Romania

2 University of Medicine and Pharmacy luliu Hatieganu, Research Center for Advanced Medicine MedFUTURE, 8 Victor Babes Str., 400012, Cluj Napoca, Romania

${ }^{3}$ Babes Bolyai University, Institute of Research in Chemistry Raluca Ripan, 30 Fantanele Str., 400294, Cluj Napoca, Romania

The aim of this work was the development of a series of glass fiber reinforced composites (FRCS) for CAD/ CAM applications in dentistry and the characterization of their structure by SEM, Raman and FTIR spectroscopy. A selection of 2 different types of resins (R1 composed from 25\%Bis-GMA, 40\%UEDMA, 35\% DMTEG and R2 composed from 65\%Bis-GMA, 35\% DMTEG) with 2 different types of hybrid filler (F1 with $42 \%$ quartz, $42 \%$ radiopaque glass and $16 \%$ hydroxyapatite and $\mathrm{F} 2$ with $90 \%$ quartz and $10 \%$ colloidal silica) and 3 different types of E type fiber glass geometries (veil $30 \mathrm{~g} / \mathrm{m}^{2}$, twill $163 \mathrm{~g} / \mathrm{m}^{2}$ and textile $300 \mathrm{~g} / \mathrm{m}^{2}$ ) in 4, 6, 8 and 10 layers were used in this in vitro study. Raman analysis, showed a powerful interaction between the polymer and the fiber glass. FTIR and SEM data revealed that the different fiber glass geometries were well incorporated inside the resin, resulting an acceptable homogeneity. Within the limitation of this study, it is possible to achieve a fiber glass reinforced composite for the use of CAD/CAM technology. Further investigation must be done in order to test all the properties of the new material.
\end{abstract}

Keywords: CAD/CAM, composite, fiber glass

In the attempt to obtain natural look-like dental restorations, that would resist to the functional conditions of the oral cavity (masticatory forces, salivary environment), several stages have been carried out over time, in which one or more of the classes of dental materials have been used. Till this moment, two classes of aesthetic dental restoration material have been highlighted: dental ceramics and composite resins. Each of these groups has numerous representatives, different by composition, properties, and consequently having different clinical indications.

CAD - CAM technology is gaining more and more ground in terms of dental restorations manufacturing. This process can be done directly in the dental office (in office systems) or in the laboratory (in Lab CAD/CAM); in this respect, different materials with various sizes and optical properties are available in order to cover a wide range of indications. Thus, ceramic blocks (feldspar ceramics, lithium disilicate or zirconium-reinforced lithium silicate ceramics), hybrid ceramics and composites are available [1].

The composites designed for CAD-CAM are more compact, exhibit fewer porosities and defects, and have a more predictable composition compared to the ones fabricated with the conventional techniques [2]. In addition, it is possible to increase the concentration of the inorganic component beyond the allowed limit in the case of the classic processed composites - to the latter, an excessive concentration of inorganic particles determines a viscosity that influences plasticity and the modelling ability in a negative way [2].

It is desired that the materials used for dental restauration to have good mechanical and optical properties in order to be integrate as much as possible in the oral structures [1].
The superiority of composite resin blocks, compared to ceramic, resides mainly in the following:

- ease of manufacture - it is estimated that a set of burs used in the CAD-CAM system allows the milling of 5-10 ceramic restorations, but over one hundred composite restorations [3]

-the possibilities of subsequent repairs, using materials with identical optical properties to the original one (same composite resins)

- materials are less susceptible to fractures when milled in thin layers [4]

- mechanical qualities: modulus of elasticity and resilience closer to dental structures

The idea of improving the properties of the composite blocks for milling has also followed other paths, such as the change in temperature and polymerization pressure: thus, applying a temperature regime of $180-200^{\circ} \mathrm{C}$ and a pressure of $300 \mathrm{MPa}$. Denser blocks with a flexural strength of 200MPa were obtained, far superior to the photopolymerized blocks or even some ceramics $[5,6]$.

Another way of improving the proprieties is to reinforce the composite with fiber glass, which promotes the transfer of stress from the polymer into the glass fibers; on the other hand, the fibers act as blocking the propagation of cracks inside the composite [7].

There are studies that have shown superior properties of composite resins reinforced with $3 D$ braided fibers compared to ceramics: milling time, cost, surface quality after milling [8-10].

Recent studies showed good fracture and flexural strength of some resins reinforced with fibers designed for milling and recommends them for thin, minimally invasive restorations; these treatments options are nowadays 
increasingly recommended in aesthetic and reconstructive dentistry, in cases of morphology correction or occlusal rehabilitation of tooth wear of different causes (erosions, abrasions, attritions) [1].

In addition, the possibility of thin layer milling is necessary for the restoration areas covering the limit of the preparation as a chamfer or even tangential to be continuous and smooth [11-13].

Despite the important developments of dental materials for CAD/CAM technology in dentistry, a quality material indicated for all clinical situations, with high reproducibility, industrially processed, operator friendly at a low cost remains a continuous challenge[14]. There is no commercial product as composite reinforced with fiber glass for CAD/CAM restauration available yet on the market

The aim of this work was the development of a series of glass fiber reinforced composites (FRCs) for CAD/CAM applications in dentistry and the characterization of their structure by SEM, Raman and FTIR spectroscopy.

\section{Experimental part}

The experimental FRCs were obtained using the combinations of silanated E-glass woven rovings and veils. The resins used for the impregnation of the glass-fibres will contain a mixture of 2,2-bis[4-(2-hydroxy-3methacryloxypropoxy) phenyl]propane (Bis-GMA), 1,6bis(methacryloxy-2-ethoxy-carbonyl-amino)-2,4,4trimethyl-hexane (UDMA) and triethylene glycol dimethacrylate TEGDMA. Radiopaque glass fillers are uniformly dispersed in the resins. The initiator system (camphorquinone and dimethyl-amino-ethyl methacrylate) for the photochemical polymerization was used. The glass fibers were be displaced in bidirectional directions.

\section{Components selection}

The selection of the resins was made regarding the composition: R1 resin composed from 25\% Bis-GMA (aromatic dimethacryate), 40\% UEDMA (urethanedimethacrylate), 35\% DMTEG (aliphatic dimethacrylate) and R2 resin composed of 65\% Bis-GMA and 35\% DMTEG.

Two different hybrid fillers were added to the resins: F1 filler consisting of $42 \%$ quart, $42 \%$ radiopaque glass ( $40 \%$ $\mathrm{SiO} ; 8 \% \mathrm{Al}_{2}$; $10 \% \mathrm{ZrO}, 12 \% \mathrm{~B}_{2} \mathrm{O}_{3} ; 16 \% \mathrm{SrO} ; 4 \% \mathrm{CaO}$; $10 \% \mathrm{CaF}_{2}+\mathrm{NaF}$ ) and $16 \%$ hydroxyapatite and $\mathrm{F} 2$ filler containing $90 \%$ quart and $10 \%$ colloidal silica.

For the fabrication of the samples, 3 different types of geometries of $\mathrm{E}$ glass fibers were used : veil $30 \mathrm{~g} / \mathrm{m}^{2}$, twill $163 \mathrm{~g} / \mathrm{m}^{2}$ and textile (woven) $300 \mathrm{~g} / \mathrm{m}^{2}$.

\section{Specimen preparation}

4 different types of FRC (FRC1-4) were obtained by mixing 2 different types of resins (R1 and R2) with 2 different types of hybrid filler (F1 and F2), then the obtained particulate composites were reinforced with 3 type of $E$ glass fibers having different geometries (architecture) by laminate lay-up process using from 4 to 10 layers (Table $1)$.

Inside of a cubic silicon matrix of $1 \mathrm{~cm}$ side, 4, 6, 8 or 10 layers of resin and fiber glass were placed one above another. After applying each layer, a light curing process of 10 seconds was done in 5 different points, with a LED lamp (420nm - 480nm wavelength, $850 \mathrm{~mW} / \mathrm{cm}^{2}-1000 \mathrm{~mW} / \mathrm{cm}^{2}$ intensity) Demi Plus, Kerr, USA. After the final photopolymerization, the fiber glass reinforced composite was extracted from the silicon mold and an additional post polymerisation process was done by inserting the mold inside a Belle Glass (Kerr, USA) oven at $135^{\circ} \mathrm{C}$ for 20 minutes.
Table 1

THE STUDIED MATERIALS

\begin{tabular}{|l|l|l|l|l|}
\hline Samples & Resin & $\begin{array}{l}\text { Hybrid } \\
\text { filler }\end{array}$ & $\begin{array}{l}\text { Fiber } \\
\text { glass } \\
\text { geometry }\end{array}$ & $\begin{array}{l}\text { Number } \\
\text { of layers }\end{array}$ \\
\hline FRC1. & R1 & F1 & Veil & 6 \\
\hline FRC2. & R2 & F2 & Veil & 10 \\
\hline FRC3. & R2 & F2 & Twill & 8 \\
\hline FRC4. & R2 & F2 & Textile & 4 \\
\hline
\end{tabular}

For each material, specimens were cut and prepared at $1 \mathrm{~mm}( \pm 0.01 \mathrm{~mm})$ thicknesses with a precision saw (IsoMet 1000 - Buehler, USA) using a diamond cutting blade for hard brittle materials and structured ceramics (diamond Wafering Blade, 15LC - Buehler, USA) at a speed of 100 rotations per minute. The samples were measured with an electronic micrometer and polished using sandpaper with increasing grits (P240, follow ed by P400, P800, P1000 and P1200, Klingspor). All samples were mesured using an electronic calliper (Hornaday).

\section{FRC samples characterisation}

The samples were investigated using the scanning electron microscope (SEM) (Inspect S, FEI Co), infrared spectroscopy (FTIR) and Raman spectroscopy.

\section{FTIR determinations}

The degree of conversion (DC) of the particulate composites was assessed by determination of the residual double bonds (RDB) using the infrared spectroscopy method. The amount of the RDB was determined as percentage of the amount of the originally methacrylic groups present in the monomer mixtures. The decrease of the absorbance intensity of the methacrylate group $C=C$ absorbance (Ameth) from $1635-1640 \mathrm{~cm}^{-1}$ was monitored. The absorption band of the phenyl group (Aarom) from $1605-1610 \mathrm{~cm}^{-1}$ was used as internal standard. The degree of conversion was calculated using the formulas:

$$
\begin{gathered}
\mathrm{RDB} \%=(\text { Ameth } / \text { Aarom }) \mathrm{F} /(\text { Ameth } / \text { Aarom }) \mid \times 100 ; \\
\text { DC } \%=100 \%-R D B \%
\end{gathered}
$$

where $\mathrm{F}$ means the final state (after curing) and I means the initial state of the material (before curing).

ATR-FTIR spectra of the particulate composites (pastes and solids) were recorded on FTIR spectrophotometer (J asco FTIR-610) equipped with an ATR (attenuated total reflectance) attachment with a horizontal ZnSe crystal (Jasco PRO400S). The resolution of the spectra was 4 $\mathrm{cm}^{-1}$. and scans were repeated 100 times. The appropriate amount of the samples was placed on the ZnSe crystal. and then the FTIR spectrum was measured.

\section{SEM characterization}

FRC samples, photopolymerized and thermic treated, were cut at $1 \mathrm{~mm}( \pm 0.01 \mathrm{~mm})$ thicknesses with a precision saw (IsoMet 1000 - Buehler, USA) and investigated using the scanning electron microscope (Inspect S, FEI Co)

\section{Raman measurements}

The Raman measurements have been performed on solid samples deposited on $\mathrm{CaF}_{2}$ substrates using a confocal Renishaw ${ }^{\circledR}$ inVia spectrometer (Renishaw plc, Wottonunder-Edge, Gloucestershire, UK), equipped with a Leica microscope (Leica Microsystems GmbH, Germany). A 20X 
(N.A. 0.40) objective has been used for spectral acquisition in the $300-1800 \mathrm{~cm}^{-1}$ interval. A $785 \mathrm{~nm}$ diode laser (Renishaw, UK) having a power less than $130 \mathrm{~mW}$ (measured at substrate surface), has been used for excitation. The acquisition time was set to $10 \mathrm{~s}$. The spectrograph was equipped with a 1200 lines/mm grating and a Peltier cooled charge coupled device (CCD) camera. Each spectrum represents the mean value of 30 individual spectra recorded on different regions of the sample. For a better interpretation of the experimental data (even from a quantitative perspective) the Raman intensities have been divided by the laser power multiplied by the exposing time. In this way the intensities variation of some vibrational peaks can provide useful information concerning the evolution of the investigated system.

\section{Results and discussions}

As can be seen from the results presented in Table 2, the photopolymerization of the composites results in resin conversion rate of the $77-78 \%$, the UDMA resin (R1) leading to slightly higher conversion rates than the (R2) bis- GMA in composition.

A significant increase in the conversion rate occurs by thermal treatment (postpolymerisation), in this case increasing by about $10 \%$.

The SEM analysis (magnification x1000, x3000 and $x 5000)$ revealed that all three different geometries of fiber glass (Veil, Twill and Textile) were well incorporated inside the resin matrix (R1F1 and R2F2), resulting an acceptable homogeneity (fig. $1 \mathrm{a}-\mathrm{d}$ ). The fact that polymer parts were found on the surface of glass fiber monofilaments, indicates an acceptable compatibility between the fiber glass and the resin matrix, where the fiber was included.
As it was mentioned at specimen preparation section each class of the composites has 2 major components: a particulate composite containing the polymers (resin) and the filling material and three types of fiberglass. Consequently, the Raman spectroscopy has been used for analyzing the four types of composites after their preparation, photopolymerization and heat treatment at $135^{\circ} \mathrm{C}$. The Raman spectra of the 4 classes of composites ( $F R C 1, F R C 2, F R C 3, F R C 4$ ) are presented in figure 2 together with the Raman spectrum of the pure polymer. All the spectra have been recorded using a NIR excitation laser $(\lambda=785 \mathrm{~nm})$.

It has been shown that the resin employed for the preparation of the FRCs contains three types of polymers: Bis-GMA, UEDMA and DMTEG. Among these, only the BisGMA polymer (which is also the most abundant one) contains two phenyl groups in its monomeric structure. As it has been demonstrated before by means of Raman measurements and quantum chemical calculations performed on different molecular species containing this functional group [15], its presence can be experimentally demonstrated by the existence of two vibrational peaks (assigned to different vibrational modes of this ring) located around $640 \mathrm{~cm}^{-1}$ and $1610 \mathrm{~cm}^{-1}$. In the spectra of the pure polymer (grey spectrum in Figure 2) these two peaks (located at 640 and $1609 \mathrm{~cm}^{-1}$ and marked with a red star) are clearly distinguishable. Very interestingly, in the Raman spectra of all four types of FRCs one can observe a major increase of the intensity of these peaks. This could be a strong evidence of the fact that the phenyl ring belonging to Bis-GMA polymers was not involved in chemical reaction during the preparation, photo- and thermal treatments of

\begin{tabular}{|l|l|l|l|l|l|}
\hline $\begin{array}{l}\text { Composite } \\
\text { Code }\end{array}$ & Resin & $\begin{array}{l}\text { Hibrid } \\
\text { filler }\end{array}$ & $\begin{array}{l}\text { CQ+ } \\
\text { DMAEM }\end{array}$ & $\begin{array}{l}\text { Post } \\
\text { polymerization }\end{array}$ & $\begin{array}{l}\text { GC } \\
\%\end{array}$ \\
\hline R1F2 & R1 & F2 & yes & No & 78.3 \\
\hline R1F2 & R1 & F2 & yes & yes & 87.8 \\
\hline R2F1 & R21 & F1 & yes & No & 77.0 \\
\hline R2F1 & R21 & F1 & yes & yes & 86.0 \\
\hline
\end{tabular}

Table 2

THE CONVERSION OF THE PARTICULATE COMPOSITES

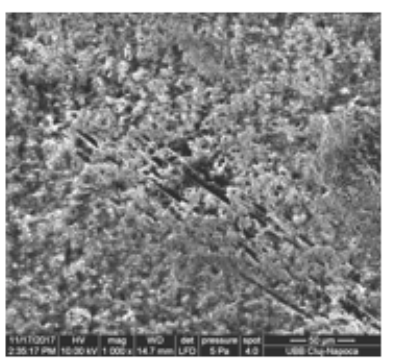

a)

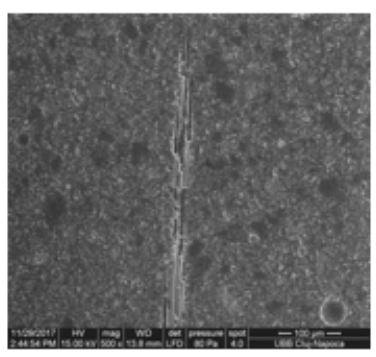

b)

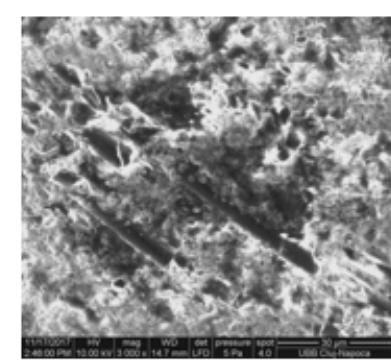

x3000

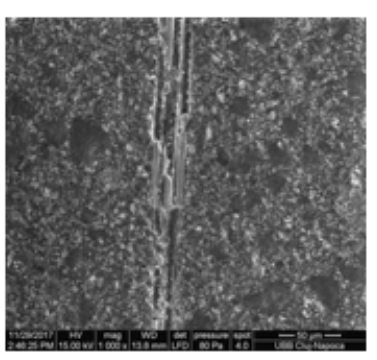

$x 1000$

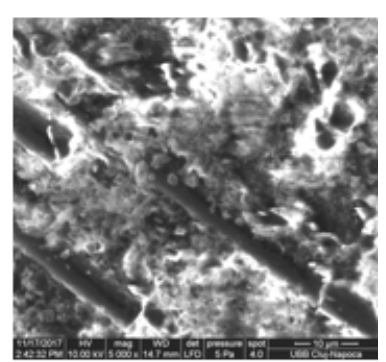

$\mathrm{x} 500 \mathrm{C}$

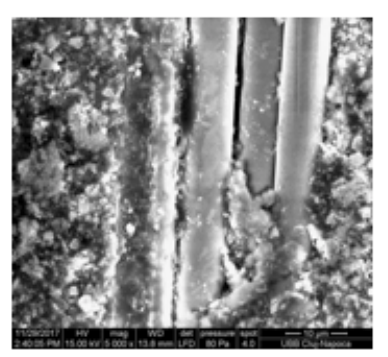

x5000
Fig. 1. SEM images of the studied materials: a) FRC1; b) FRC2 


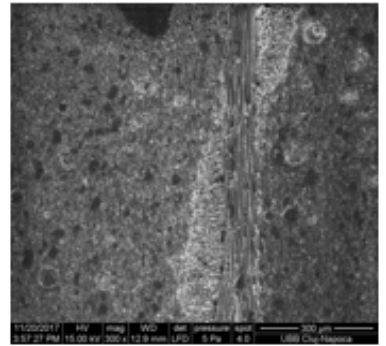

c)

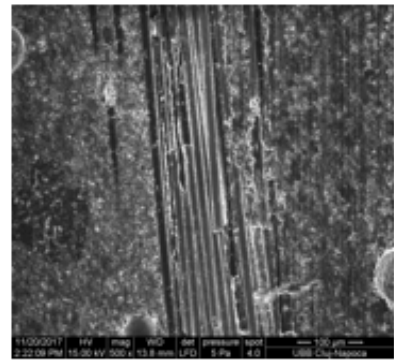

d)

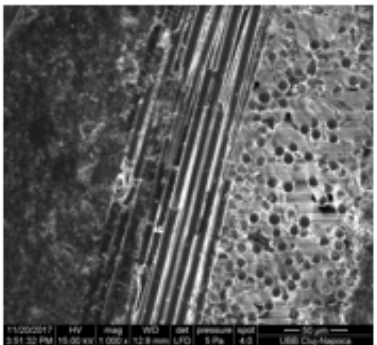

$\mathrm{x} 1000$

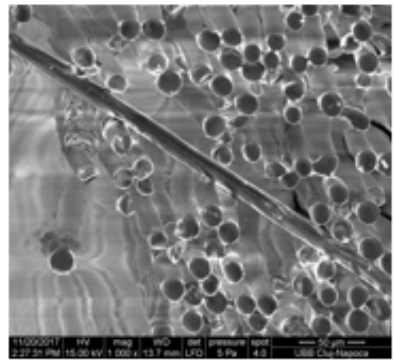

$\mathrm{x} 1000$

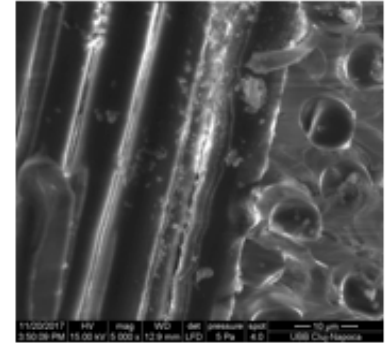

x5000

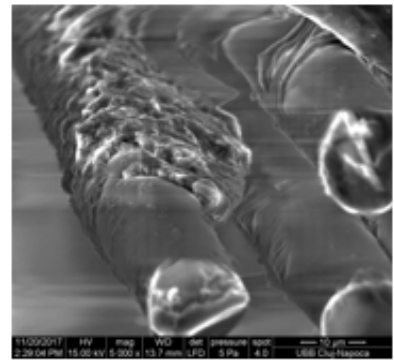

x5000
Fig. 1. SEM images of the studied materials: c) FRC3; d) FRC4.

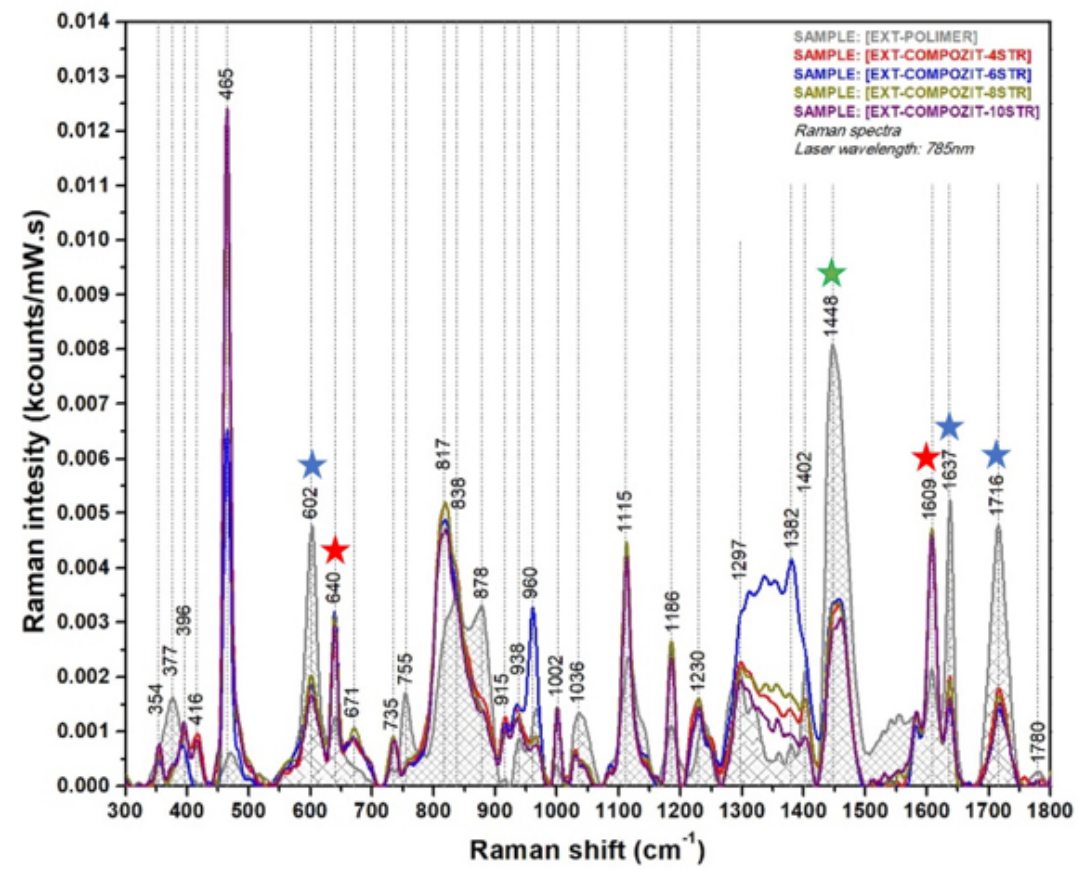

Fig. 2. Raman spectra of the pure polymers (grey spectrum) and of the four classes of composites (FRC1-4) recorded using a $785 \mathrm{~nm}$ excitation wavelength

the composites. The same behaviour has been observed in the case of the peak located at $1115 \mathrm{~cm}^{-1}$ and assigned to a antisymmetric stretch of the C-O-C group.

On the other hand, another three very intense peaks located at 602, 1637 and $1712 \mathrm{~cm}-1$ (marked with a blue star) are detected in the Raman spectrum of pure polymer. The evolution of the Raman intensity of these three peaks, assigned to vibrational modes of $\mathrm{O}-\mathrm{C}=\mathrm{O}$ (bending), $\mathrm{C}=\mathrm{C}$ (aliphatic stretch) and $\mathrm{C}=0$ (carbonyl ester stretch) groups, is completely opposite with the one observed in the case of $640 \& 1609 \mathrm{~cm}^{-1}$ peaks. This could be related to the involvement of this chemical bonds in the formation of the composite, as it was previously suggested [16].

But the most obvious decrease can be observed in the case of the $1448 \mathrm{~cm}^{-1}$ peak, assigned to $\mathrm{CH}_{2}$ and $\mathrm{CH}_{3}$ groups [17], suggesting that these two groups are strongly involved in the synthesis process of the composites.

\section{Conclusions}

Within the limitation of this study, the investigations performed in the present paper showed promising results and proved that it is possible to achieve fiber glass reinforced composite for the use with CAD/CAM technology. Further investigation must be done in order to test all the properties of the new material.

Raman spectroscopy has been successfully employed for the characterization of the composites. By analysing the spectrum acquired on pure polymers with those recorded on the four classes of the composites one could get useful information related to the functional groups involved in their synthesis process.

Acknowledgment:: This work was supported by the Romanian National Authority for Scientific Research and Innovation, UEFISCDI, project PN-III-P2-2.1-PED-2016-1936 


\section{References}

1. PETERSEN R, LIU pr. 3d-woven fiber-reinforced composite for cad/ cam dental application. Sampe J. 2016 May ; 2016.

2. LI RWL, CHOW TW, MATINLINNA JP. Ceramic Dental Biomaterials and CAD/CAM Technology: State of the Art. J ournal of Prosthodontic Research. 2014; 58:208-216.

3. RUSSE ND, SADOUN MJ. Resin-composite Blocks for Dental CAD/ CAM Applications J Dent Res 93(12) 2014

4. TSITROU EA, NORTHEAST SE, VAN NOORT R (2007). BrittlenesS index of machinable dental materials and its relation to the marginal chipping factor. J Dent 35:897-902.

5 COLDEA A, SWAIN MV, THIEL N (2013b). Mechanical properties of polymer infiltrated-ceramic-network materials. Dent Mater 29:419426.

6. NGUYEN JF, MIGONNEY V, RUSE ND, SADOUN M (2013). Properties of experimental urethane dimethacrylate-based dental resin composite blocks obtained via thermo-polymerization under high pressure. Dent Mater 29:535-541.

7. KOHJI NAGATA, SUFYAN K. GAROUSHI, PEKKA K. VALLITTU, NORIYUKI WAKABAYASHI, HIDEKAZU TAKAHASHI \& LIPPO V. J . Lassila Fracture behavior of single-structure fiberreinforced composite restorations, Acta Biomaterialia Odontologica Scandinavica, 2:1, 2016, 118-124,

8. PETERSEN RC, LIU P-R. Mechanical Properties Comparing Composite Fiber Length to Amalgam. J ournal of Composites In Press 682536. 2016

9. SANO H, CIUCCHI B, MATTHEWS WG, PASHLEY DH. Tensile Properties of Mineralized and Demineralized Human and Bovine Dentin. Journal of Dental Research. 1994; 73:1205-1211.
10. AWADA A, NATHANSON D. Mechanical properties of resin-ceramic CAD/CAM restorative materials. J Prosthet Dent 2015;114:587-593

11. NATHANSON 3 POTICNY DJ , KLIM J. CAD/CAM in-office technology: innovations after 25 years for predictable, esthetic outcomes. J Am Dent Assoc 2010;141: 5S-9S.

12. FERRACANE JL (2011). Resin composite-state of the art. Dent Mater 27:29-38.

13. BJ ORK N, EKSTRAND K, RUYTER IE. Implant-fixed dental bridges from carbon/graphite reinforced poly(methyl methacrylate). Biomaterials 1986;7:73-75.

14. LAZAR MA, FLIP M, VLASSA MC, SORCOI L, CAMPIAN RS, Prejmenrean $C$, Developement and characterisation of a new fiberreinforced biocomposites for cranial bone reconstruction, Romanian J ournal of Materials 2016, 46 (2),142 - 151

15. FARCASA, IACOVITA C, VINTELER E, CHIS V, STIUFIUC R, LUCACIU $C M$. The influence of the molecular structure modifications on vibrational properties of some beta-blockers: a combined Raman and DFT study. Journal of Spectroscopy. 2016; 2016:1-9.

16. NAVARRA CO, CADENARO M, FRASSETTO A, FONTANIVE L, DI LENARDA R, BRESCHI L, Degree of conversion of self-etching adesives: in-situ micro-Raman analysis. Operative Dentistry. 2016; $41: 3$

17. STIUFIUC R, IACOVITA C, STIUFIUC G, FLOREA A, ACHIM M, LUCACIU CM. A new class of pegylated plasmonic liposomes: Synthesis and characterization. Journal of Colloid and Interface Science. 2015;437:17-23.

Manuscript received: 10.04 .2019 